\title{
AN APPLICATION OF TIROS CLOUD OBSERVATIONS IN SPARSE DATA REGIONS ${ }^{1}$
}

\author{
MAJOR FORREST R. MILLER 2 \\ International Meteorological Centre, International Indian Ocean Expedition, Bombay, India \\ [Manuscript received April 5, 1963, revised July 8, 1963]
}

ABSTRACT

\begin{abstract}
The streaming appearance of the earth's cloud cover is strikingly evident from TIROS photographs suggesting that broadscale synoptic patterns in the form of major troughs and ridges can be deduced. Several case studies were made to determine the feasibility of deducing from TIROS nephanalyses and photos major flow patterns at $500 \mathrm{mb}$. by applying kinematic analysis techniques. Streamline and isotach analyses were inferred from nephanalyses without prior knowledge of the actual synoptic situations. Results show that a rcasonable estimate of 500-mb. largescale synoptic patterns can often be obtained. When deduced flow directions and speeds, and estimated central heights of vortices are introdueed into a numerical analysis computer program, using as the first guess over a sparse data region the 500 -mb. monthly mean heights, definitive contour analyses are obtained.
\end{abstract}

\section{INTRODUCTION}

In 1926 Sir Napier Shaw [9] wrote". . . we must refer to clouds as being one of the most obvious sources of information about the free air". However, because cloud forms have been primarily classified according to recognizable shapes and textures, little was ever observed or reported about their alignment relative to the wind after the era of the nephoscope. Thus, until recently, the opinion prevailed that a relatively small portion of the earth's cloud cover exhibited banded or striated forms along the flow. Exceptions to this situation, of course, were recognized to exist in the vicinity of well organized cyclones, along jet streams, and in the trade wind belt.

The first photographs from rockets launched over southwestern United States showed definite cloud "streets" [5]. Almost all earth viewing photographs from satellites have revealed the great streakiness of cloud systems $[1,4,6,8,13]$. Large masses of stratiform clouds as well as cumuliform clouds, at multiple levels, have shown internal elongated and banded structures in TIROS photographs.

The "streaming" appearance of the earth's cloud cover is strikingly evident when mosaics of TIROS photographs are displayed. A TIROS composite covering the Southern Hemisphere oceans presented by Oliver [6] dramatically pictures the immense cyclonic vortices associated with the "roaring forties". The general sense of large-scale atmospheric motion is evident in such portrayals suggesting that some form of synoptic

1 This work was conducted over a two-year period from May 1960 as part of a study to juvestigate techniques of applying TIROS data to analysis over sparse data regions.

2 Former assignment: Detachment 51, 1210tr Weather Squadron, Air Weather Service, USAF. patterns in terms of major troughs and ridges can be deduced. Even the absence of widespread middle and high level cloudiness over certain regions can be meaningful synoptically if viewed in conjunction with large cloud masses which can be interpreted.

Since TIROS II was placed into orbit, the quality of nephanalyses from satellite readout stations has improved markedly. Although there is no substitute for rectified TIROS photographs in mosaic form, facsimile transmitted nephanalyses have provided meteorologists with excellent supplementary and timely information about the upper atmosphere, particularly over sparse data regions. The problem of finding a suitable procedure for estimating upper-level flow patterns on a global scale from TIROS data over sparse data regions is indeed challenging.

\section{METHOD}

Several case studies have been made using TIROS cloud data which were received in the form of nephanalyses transmitted by facsimile from the readout sites. Whenever TIROS cloud photographs were available, they served as additional information for the investigation. The primary objective was to determine the feasibility of deducing from satellite cloud data an estimate of the large-scale upper-air flow patterns over sparse data regions. Kinematic analyses were made over the sparse data regions of the Atlantic and Pacific Oceans where conventional analyses are available.

Nephanalyses consisting of several swaths of TIROS data were transferred to standard upper-air plotting charts. A streamline analysis for the $500-\mathrm{mb}$. level was then inferred from the patterns of the major cloud masses. For example, where cloud elements indicated marked cycloni- 
cally curved patterns a streamline trough or vortex was drawn. In general, streamlines were drawn along the major axis of cloud bands interpreted to be at the middle and upper levels of the atmosphere. In those regions between troughs and estimated to be under the influence of anticyclonic motion, by virtue of being devoid of identifiable upper-level cloud systems, anticyclonic streamline patterns in the form of ridges or anticyclonic singularities were drawn. Neutral points, corresponding to cols in the pressure field; were located in appropriate places between vortices. Monthly resultant upper wind charts [12] also served as a guide and an analytical control in determining the proper streamline patterns and placement, of centers, particularly in regions adjacent to but not covered by the nephanalysis. The $500-\mathrm{mb}$. level was chosen as the analysis level because it represents a middle level in the atmosphere and the derived kinematic analysis could be introduced into the $500-\mathrm{mb}$. numerical analysis program at the National Meteorological Center (NMC), Suitland, Md.

An isotach field was constructed over the streamlines by applying isotach models since the cloud patterns do not directly reflect the speed distribution. The models were based on sound kinematic principles and empirical relationships between synoptic cloud patterns and the wind field. For example, minimum speed centers coincide with streamline vortices and major axes of maximum speed centers are generally oriented along the upper-level flow. The speed maxima in the westerlies are found aloft to the north of surface positions of the polar front in the Northern Hemisphere.

Although an application of kinematic analysis in this manner is subjective, a series of tests demonstrated that several skilled analysts agreed on the broad-scale streamline interpretation of a particular nephanalysis. The most subjective part of this approach was obtaining a representative speed field which was consistent with both the streamlines and TIROS cloud data. In order to make a reasonable estimate of the speed field, a type of analog system was used. The technique applied was to find in the daily historical map series upper-air height patterns at $500 \mathrm{mb}$. which were similar to those deduced from the nephanalyses. Several analogous situations were examined and a typical speed pattern was obtained. The derived isotach pattern was superimposed over and adjusted to the streamlines. To complete the analysis, estimates of $500-\mathrm{mb}$. heights for the cyclonic and anticyclonic streamline centers were obtained from the analog situations in the historical file.

Two series covering analyses of three or more days are discussed in which this method was used. In addition, a single streamline-nephanalysis is shown to illustrate that large-scale cloud patterns reflect circulation changes with time as well as in space. In all of the situations investigated by this method, conventional surface and upper-air analyses were not known or consulted in any way prior to performing the streamline-jsotach analyses.
The only data referenced during the analysis period were the nephanalyses for each situation, the Weather Bureau's monthly normal charts $[10]$ and $500-\mathrm{mb}$. streamlines of mean resultant winds [12].

The streamlines and isotachs shown in the figures of this text are the solid curves (with arrows) and dashed lines respectively. Isotach patterns are displayed on only the single nephanalyses of figure 1 and the last charts of the two series described in sections 5 and 6 .

The general intent in this paper has been to apply streamline models, based on experience, which are more applicable to the lower $30,000 \mathrm{ft}$. of the atmosphere. For example, anticyclonic vortices generally show some outdraft characteristic while cyclones are characterized by streamlines spiraling in toward the center. Since it is not possible to determine the rate of inflow or outfiow near the center of vortices from TIROS photos, the following procedure was used to illustrate schematically systems in various stages of development. In some analyses the streamline spiraling into the center of a 500-mb. cyclonic vortex have been somewhat exaggerated to give the impression of a system in an accelerating or developing stage. In other cases the amount of streamline convergence was reduced where it was deduced that the system was in a mature or decaying stage. The same general outflow characteristic was given to all anticyclonic vortices. However, even though there were definite uncertainties about the rate of spiraling of the streamlines near the centers, the derived winds yielded numerical analyses comparable to NMC analyses based on radiosonde data.

Detailed composite cloud photographs for the situations described were not available for inclusion. Originals and copies of TIROS 35- $\mathrm{mm}$. films covering each orbit shown by the nephanalyses in this paper are on file at the National Weather Satellite Center, Washington, D.C.

\section{ASSUMPTIONS}

In this work the primary effort was directed toward deducing from TIROS cloud data, the main trough and ridge patterns of the middle troposphere. There has been no attempt to interpret small-scale synoptic features from the cloud patterns. It is realised that many TIROS cloud photographs exhibt some internal banded structures transverse to flow through the middle levels and lines of cumulus elements paralleling a shear vector of the winds in the convective level. However, the assumptions presented below are considered reasonably valid when applied to macro-scale weather and flow patterns:

a. The orientation and distribution of major cloud masses reflect the broad-scale flow of the atmosphere. From striated patterns and elongated elements or "fingers" of clouds the general direction of flow can be inferred.

$b$. In regions lacking extensive masses of stratiform, middle, and high clouds and showing only small-scale cumulus, the flow is generally assumed to be associated 
with large-scale anticyclonic circulations witbin limits, namely: the placement of a ridge or anticyclone center under such circumstances is dependent on the estimated positions of troughs inferred where clouds are present and the expected climatological positions of the subtropical anticyclones.

c. Broadscale synoptic patterns as interpreted from TIROS upper-level cloud patterns are fairly representative of the flow throughout a deep layer, i.e., above the convective levels and below the cirrus levels. This assumption implies that macro-scale flow patterns exhibit relatively small directional shears within the middle layers.

d. Major cloud masses of the upper and middle troposphere can, in a very general way, be distinguished from low-level clouds. New techniques now under development for analyzing TIROS infrared data [3] will provide assistance in delineating cloud types and heights.

$e$. A judicious application of climatology and analog techniques in finding representative isotach patterns is also assumed.

\section{TIROS II PHOTOGRAPHED UPPER-AIR CHANGES}

A double composite nephanalysis for December 4 and 5, 1960 is shown in figure 1. The composite was originally two separate nephanalyses from December 4 through several hours beyond December 5. In figure 1 broken to overcast stratiform clouds for December 4 are heavily shaded; those observed by TIROS on December 5 are lightly shaded. Originally this composite was color coded. Patches of clouds reported on both days to be scattered to broken are hatched. Cross hatching represents this condition over the same region on both days. ${ }^{3}$ This example is included to illustrate how large cloud masses, showing changes in alignment in the photos and nephanalyses, can be interpreted in terms of upper flow patterns. Two prominent areas showing realignment and movement of large cloud masses identifiable on both days are shown in figure 1.

Over northwestern portions of Africa $\left(15^{\circ} \mathrm{N},-30^{\circ} \mathrm{N}\right.$; $0^{\circ}-15^{\circ} \mathrm{E}$.) major cloud elements were oriented northeastsouthwest on December 4. However, by the time TIROS traversed this region again $24 \mathrm{hr}$. later, these cloud patterns had assumed a more north-south or even northwestsoutheast orientation. In contrast, scattered to clear conditions were photographed over the northwestern part of Africa (vicinity of $20^{\circ} \mathrm{N}, 10^{\circ} \mathrm{W}$.) on both days. Off the African coast in the Atlantic, large cloud masses in an apparent north-south elongation persisted during the 4th and 5th of December. Undoubtedly some of these coastal cloud masses consisted of low-level stratus on the east side of the Atlantic subtropical anticyclone. However, a definite cyclonic turning of the major cloud elements over Africa $\left(20^{\circ} \mathrm{N} .-35^{\circ} \mathrm{N}, ; 5^{\circ} \mathrm{W} .-10^{\circ} \mathrm{E}\right.$.) was

3 The system, applied to nephanalyses in this report, for reporting amount and types of clouds observed from satellites is described in "Depiction of Satellite Cloud Observations for Facsimile Transmission", Forecast Development Report No. 1, U.S. Weather Bureau, Washington, D.C., Deeember 1860, 25 pp.

$695-275-63-4$ viewed by TIROS on December 5, particularly to the east of the streamline center of the cyclone. Recent case studies $[2,7,8]$ have shown TIROS views of mature cyclones with relatively clear central portions and extensive moisture bands around the periphery.

Thus, the distribution and reorientation of clouds over Africa were interpreted to reflect the formation of a cut-off cold Low with a closed circulation becoming established after December 4 . The $500-\mathrm{mb}$. charts from the National Meteorological Center (NMC) showed a well defined trough moving over the African coast between December 3 and 4. By December 5 (fig. 2), a low-latitude, upperlevel cyclone had developed with its center in about the same position as shown by the streamline center over northwestern Africa in figure 1. The $500-\mathrm{mb}$. low center persisted for several days. It should also be noted that over the Mediterranean Sea, eastern Africa, and Egypt (extreme right of fig. 1), generally clear conditions were reported on the nephanalysis, i.e., no large masses of stratiform clouds were reported. This region was interpreted as being associated with an upper-level ridge as shown by the streamlines.

The other region showing some movement and realignment of cloud masses was over the Atlantic, off the east coast of the United States. Scattered to broken cumulus type clouds were observed along the east coast $\left(20^{\circ} \mathrm{N} .-40^{\circ} \mathrm{N}\right.$.; $70^{\circ} \mathrm{W} .-80^{\circ} \mathrm{W}$.) on both days. Farther east a broad, overcast band of stratiform clouds oriented north-south marked the leading edge of a frontal zone and associated upper-level trough on December 4 (shown in fig. 1 by the heavy shaded region along $60^{\circ} \mathrm{W}$.). On the next day this same band of cloudiness had shifted $5^{\circ}$ of longitude eastward between $15^{\circ} \mathrm{N}$. and $30^{\circ} \mathrm{N}$. and was apparently oriented more nearly northeast-southwest. The northern portion of this cloud mass was not viewed by the TIROS camera on December 5. In the central portion of figure 1 between $15^{\circ} \mathrm{N}$. and $30^{\circ} \mathrm{N}$, the two days' composite seemed to show a rather random distribution of clouds at first analysis, but a close study indicated that many of the major cloud elements had their major axes elongated in an east-west direction. A general eastward drift and convergence of the cloud masses toward the low center was inferred and is represented by the streamlines. The streamline and isotach analyses in figure 1 were deduced from the composite nephanalysis for December 5, 1960 (the lightly shaded cloud masses). The streamline analysis agreed with the NMC $500-\mathrm{mb}$. height analysis shown in figure 2. In particular, the placement of the streamline troughs and ridges was in agreement, but their amplitudes were greater in the NMC analysis on December 5. The relatively clear areas along $50^{\circ} \mathrm{W}$. and $10^{\circ} \mathrm{E}$. to $20^{\circ} \mathrm{E}$. were verified to be associated with ridges.

\section{STREAMLINE-NEPHANALYSES OF MAY 19-21, 1960}

Figure 3 represents a combined streamline-nephanalysis for May 19, 1960. The period covered by the satellite 


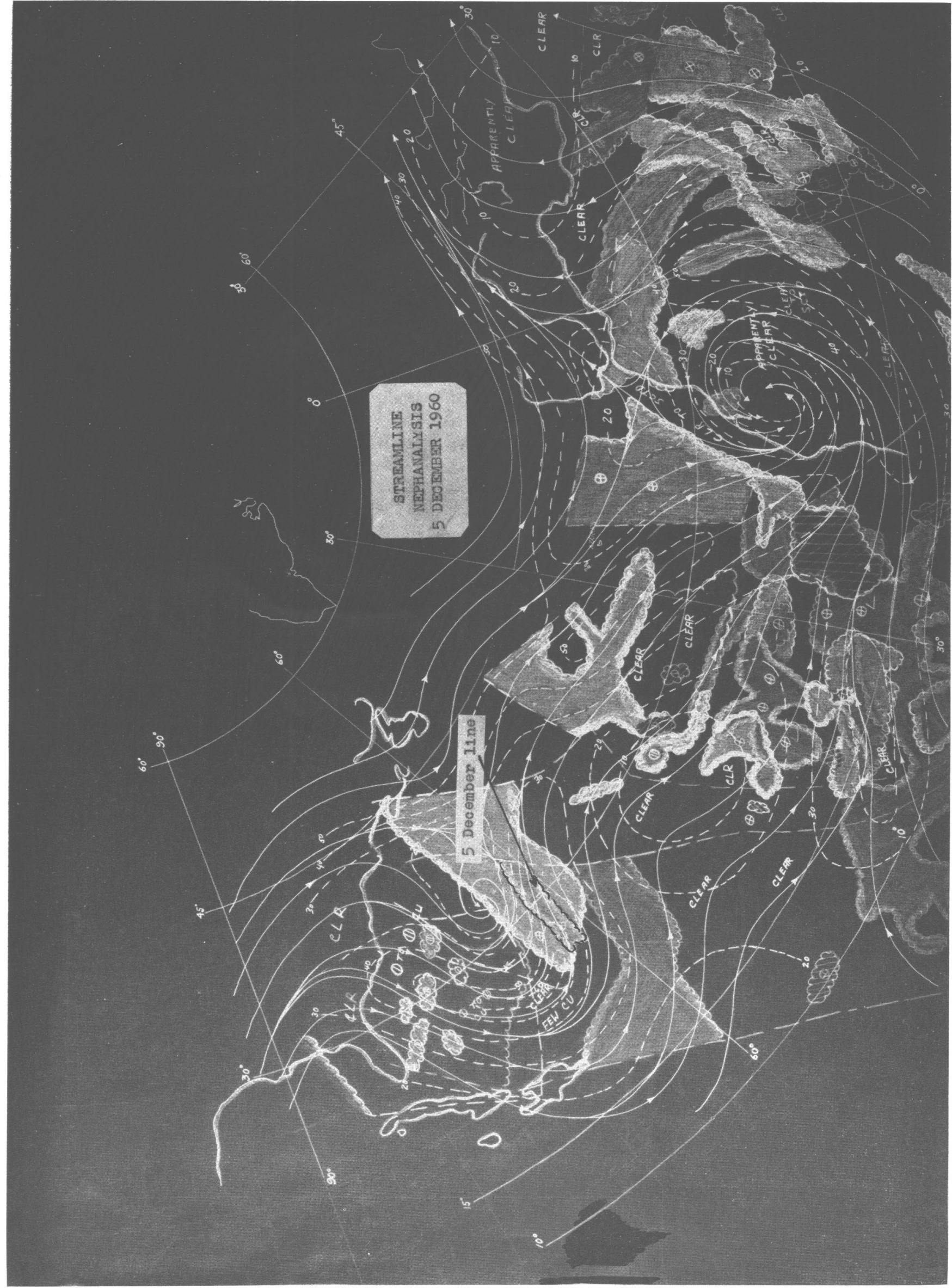




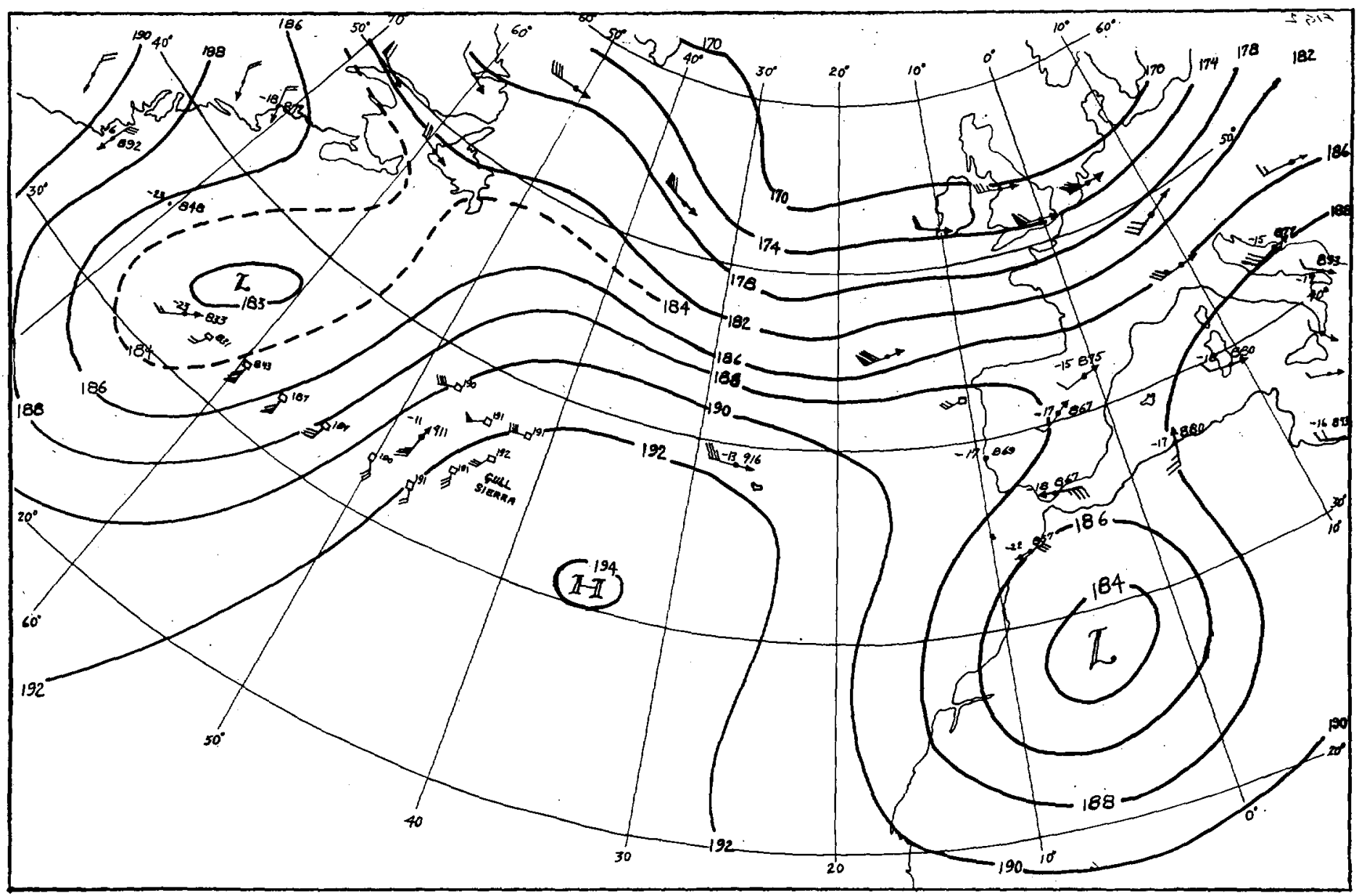

Figure 2.-Conventional 500-mb. analysis for 0000 GMT, December 5, 1960 from the National Meteorological Center.

data extends from a few hours before $0000 \mathrm{GMT}$ to a few hours after on May 19. This analysis helped to establish continuity for subsequent analyses on May 20 and 21 shown in figures 4 and 5 .

Heavily shaded areas (white on the figure) represent overcast stratiform clouds, and large patches of scattered to broken cumuliform are shown as hatched areas. Light shaded areas (gray) depict scattered to broken stratiform clouds. Few or scattered individual cumulus clouds are represented by the cumulus symbols over a given region. This same delineation scheme is followed in figures 4 and 5. For May 19 (fig. 3) cloud data from only three orbital passes were available. To the north and south of the Pacific region covered by 'TIROS data, the $500-\mathrm{mb}$. resultant wind chart [12] for May was relerenced in drawing the streamlines. The isotach analysis (dashed lines) is displayed with the streamlines in only the final chart (fig. 5) although originally isotachs were drawn on the other analyses as well. The marked frontal cloud structure of the central Pacific Low shown in figure 3 was interpreted as part of a deepening cyclonic system. The general widespread cloudiness (but banded to some degree) in eastern Asia seemed to be associated with a relatively new system. In the Gulf of Alaska the primary frontal band apparently had moved completely out of the main cyclonic circulation and extended northeastward into Canada. There were some well defined cyclonically turning cloud bands and lines showing a definite trough and the general extent of the cyclonic circulation. Elsewhere between low centers small amounts of stratiform clouds were interpreted to be associated with northwesterly flow.

The nephanalysis for 0000 GMT, May 20, 1960 (fig. 4) showed some reintensification of the front in the eastern Pacific. The heavy frontal cloud bands in the central Pacific revealed an outstanding example of the occluding process with the primary moisture band wrapping up, over, and around the central cyclone. Several scattered "bright" cloud patterns were strung out to the southwest from the polar front over the eastern Pacific. Widespread stratiform clouds continued to prevail over the northwestern Pacific, but a definite banded structure with cyclonic curvature could be discerned.

The streamline neutral points and subtropical anticyclonic centers south of $30^{\circ} \mathrm{N}$. latitude in figures 3,4 , and 5 were based on their climatological positions for May at $500 \mathrm{mb}$. and adjusted to fit the streamline pattern inferred from the nephanalyses. 


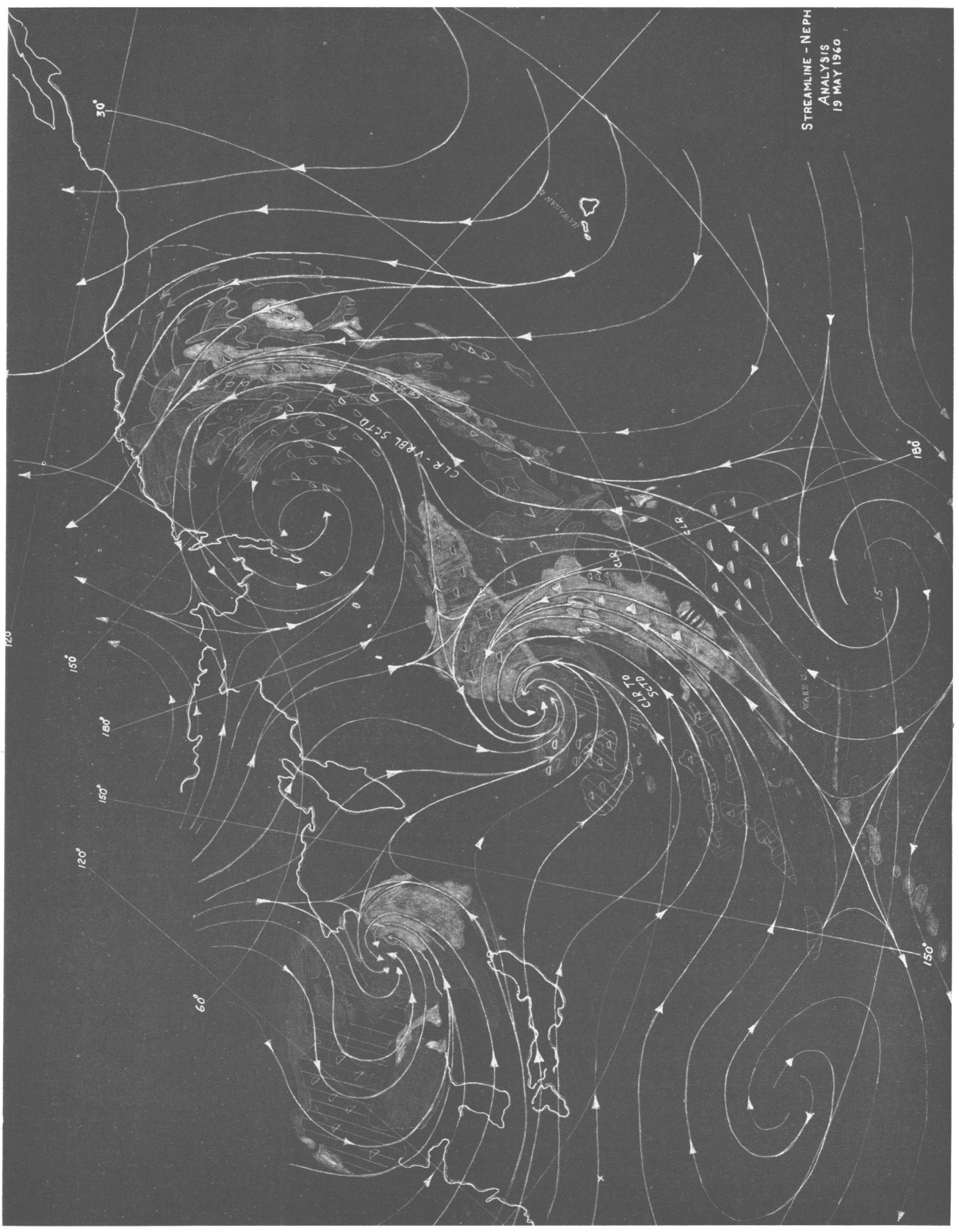

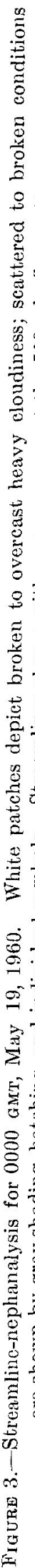




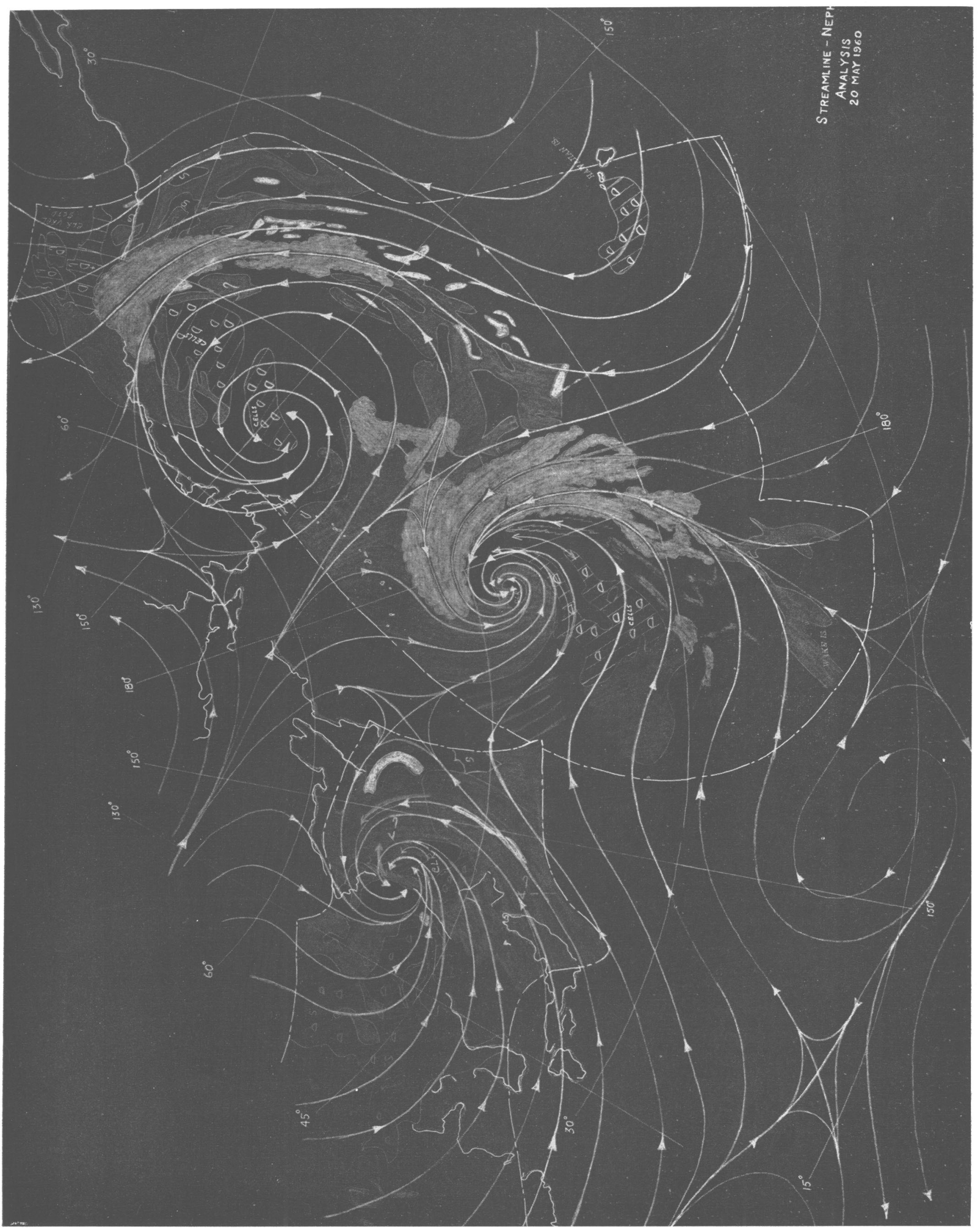

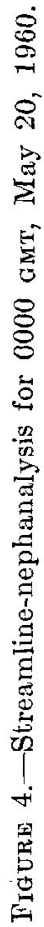




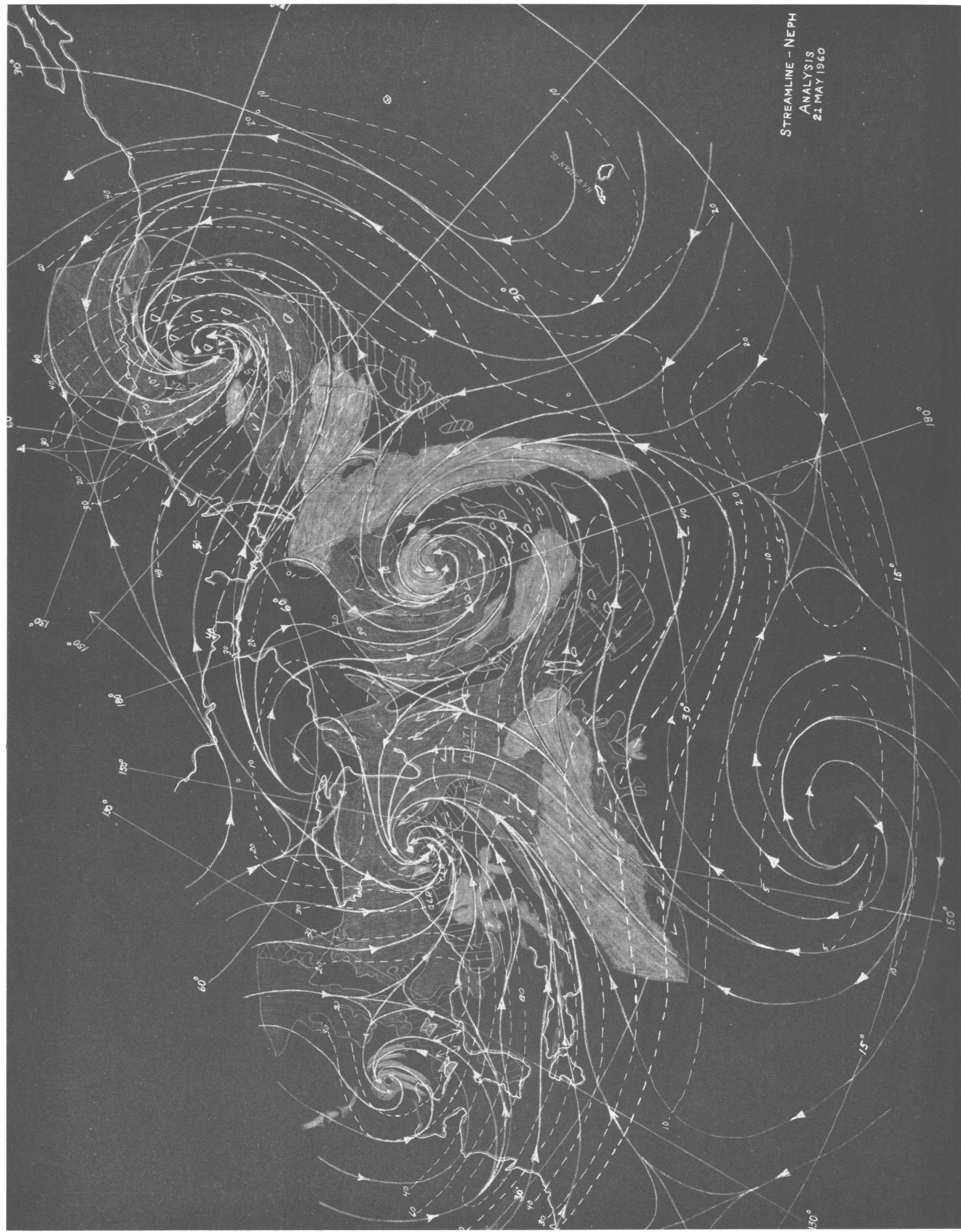


The nephanalysis for 0000 aMT, May 21, 1960 (fig. 5) revealed more widespread cloudiness throughout the central and western Pacific. From this nephanalysis it was concluded that the major portion of the eastern Pacific frontal band moved out from under the satellite track leaving only scattered remnants of the old cyclonic circulation. The heavy cloud pattern in the central Pacific showed the frontal system to be occluded and moving to the northeast away from the upper Low. However, some large cloud masses and other cloud striations around the periphery of the center marked the cyclone's central position. An extensive heavy overcast southeast of Japan was part of a polar frontal system for which there were no TIROS data on the two previous days. This frontal system was later verified from conventional analyses as intensifying under a strong jet on May 21 . The main western Pacific 500-mb. low center was over Sakhalin on May 21. There was strong evidence in the banded cloud patterns of a new cyclone circulation over Manchuria developing in the westward extension of the Sakhalin Low. Conventional 500-mb. charts from the National Meteorological Center on May 21 revealed a trough extending southwest into Manchuria. Additional details concerning verification of analyses for this case study are presented in section 7 .

The streamline-isotach analyses in figures 3,4 , and 5 represent the $500-\mathrm{mb}$. flow as deduced from the nephanalyses described above. All three charts show, in some state of intensification or decay, the classical example of the polar front family of waves extending across the Pacific Composites of TIROS photographs from which the nephanalyses of this series have been made up have appeared in several publications $[1,11]$; they have become some of the classic examples from the TIROS I series.

\section{STREAMLINE-NEPHANALYSIS IN THE PACIFIC, AUGUST 23-25, 1961}

The discussion of the May 19-21, 1960 series was based primarily on nephanalyses and TIROS photographs of a well defined family of polar frontal systems in various stages of development over the mid-central Pacific. In order to expand further on the streamline-isotach approach as applied to nephanalyses, the following 4-day series, which covers most of the Pacific Ocean and adjacent land areas, is presented.

This series is based on nephanalyses covering the period August 23 through 25, 1961. During this period TIROS III traversed the Pacific Ocean region from the equator to near $50^{\circ} \mathrm{N}$. recording cloud structures of the southeast Asia monsoon and continuing eastward over several large regions of cloudiness over the Pacific and the United States. These nephanalyses are some of the most comprehensive and best documented TIROS series covering the Pacific Ocean region now on record. In most cases the composites cover a period of approximately $10 \mathrm{hr}$. TIROS III, while on its orbital trajectories over the Pacific and United States, swept through about three passes before midnight and three after midnight of the day designated on each chart of figures 6 through 9 . The same cloud shading scheme described in section 5 for the May series was used in this series.

One of the most significant features in figures $6,7,8$, and 9 of this series, is the widespread band of heavy, stratiform cloudiness between latitudes $35^{\circ} \mathrm{N}$. and $50^{\circ} \mathrm{N}$. stretching across the North Pacific. Periodic interruptions or elongated breaks in these heavy overcast regions can be seen where data are available on all charts in this belt from China eastward to the west coast of the United States. Many of the heavy cloud areas are characterized by banded elements with apparent cyclonic curvature. The polar front, with periodic breaks in the cloud activity, appears to show up distinctly in all nephanalyses, particularly those of figures 7 and 9 . The most marked polar frontal system appears in the nephanalyses between $30^{\circ} \mathrm{N}$. and $50^{\circ} \mathrm{N}$. from $150^{\circ} \mathrm{W}$. to $150^{\circ} \mathrm{E}$.

Another outstanding feature common to all charts of this series is the general lack of extensive layers of stratiform middle and high clouds over the Pacific Ocean, eastern China, and southwestern United States between $20^{\circ} \mathrm{N}$. and $35^{\circ} \mathrm{N}$. Over this same region nephanalyses show orderly lines of cumulus and other singular large cloud elements which can be seen converging, with some anticyclonic curvature, into the main mass of polar front clouds. These elongated narrow lines of clouds, oriented generally southwest to northeast, are particularly prevalent on August 22 and 23 (figs. 6 and 7). On August 22 near $35^{\circ} \mathrm{N} ., 136^{\circ} \mathrm{W}$. several lines of clouds revealed a previously undetected cyclonic circulation which appeared to be less well defined on August 23 .

Since TIROS cloud data were missing over large sections of the Tropies south of $25^{\circ} \mathrm{N}$, it was possible to make only generalized deductions about the flow based on cloud structures. Inferences from cloud patterns available tied in with climatology and the analyses over extratropical regions served as the primary guide in estimating the streamline troughs and ridges south of the anticyclonic ridge for the $500-\mathrm{mb}$. level. In August the $500-\mathrm{mb}$. level lies well within the easterlies over most regions south of $25^{\circ} \mathrm{N}$. Hence, it is possible to estimate a reasonable flow pattern at this level, considering nephanalyses and the situation to the north, without getting involved with the transition (between easterlies and westerlies) zone. However, this is not possible in the spring, fall, and winter seasons [12].

Figure 10 shows the combined $500-\mathrm{mb}$. and surface analyses for $1200 \mathrm{GMT}$, August 24; 1961, prepared at the National Meteorological Center. It is apparent from figure 10 that on the 24 th a series of polar waves was moving out of Asia and across the Pacific between $35^{\circ} \mathrm{N}$. and $50^{\circ} \mathrm{N}$. The subtropical ridge was pronounced and extended westward from the United States to China in multi-cellular systems. Southeast of Formosa typhoon Lorna was moving slowly west-northwest.

The typhoon was not detected from the nephanalysis. 


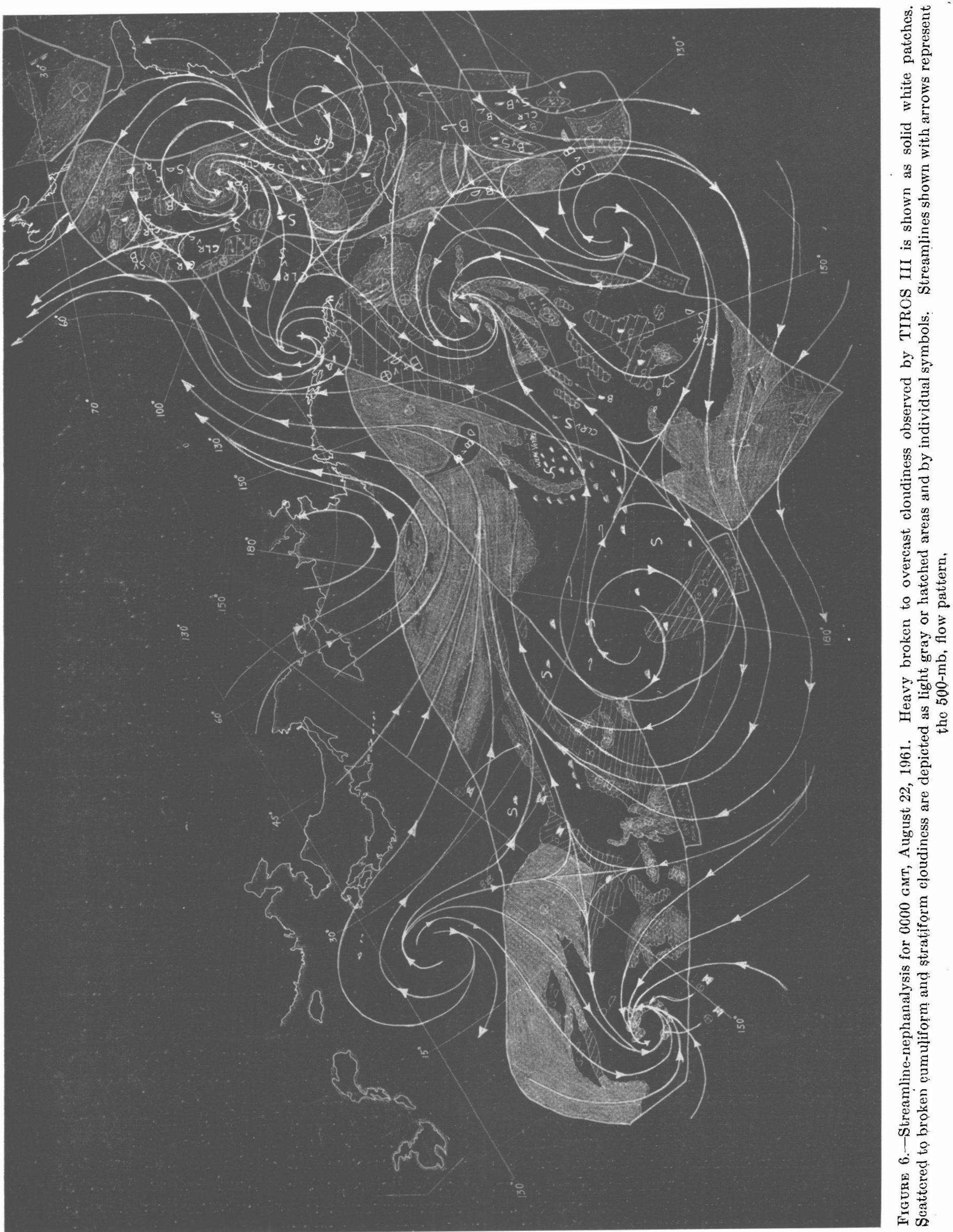




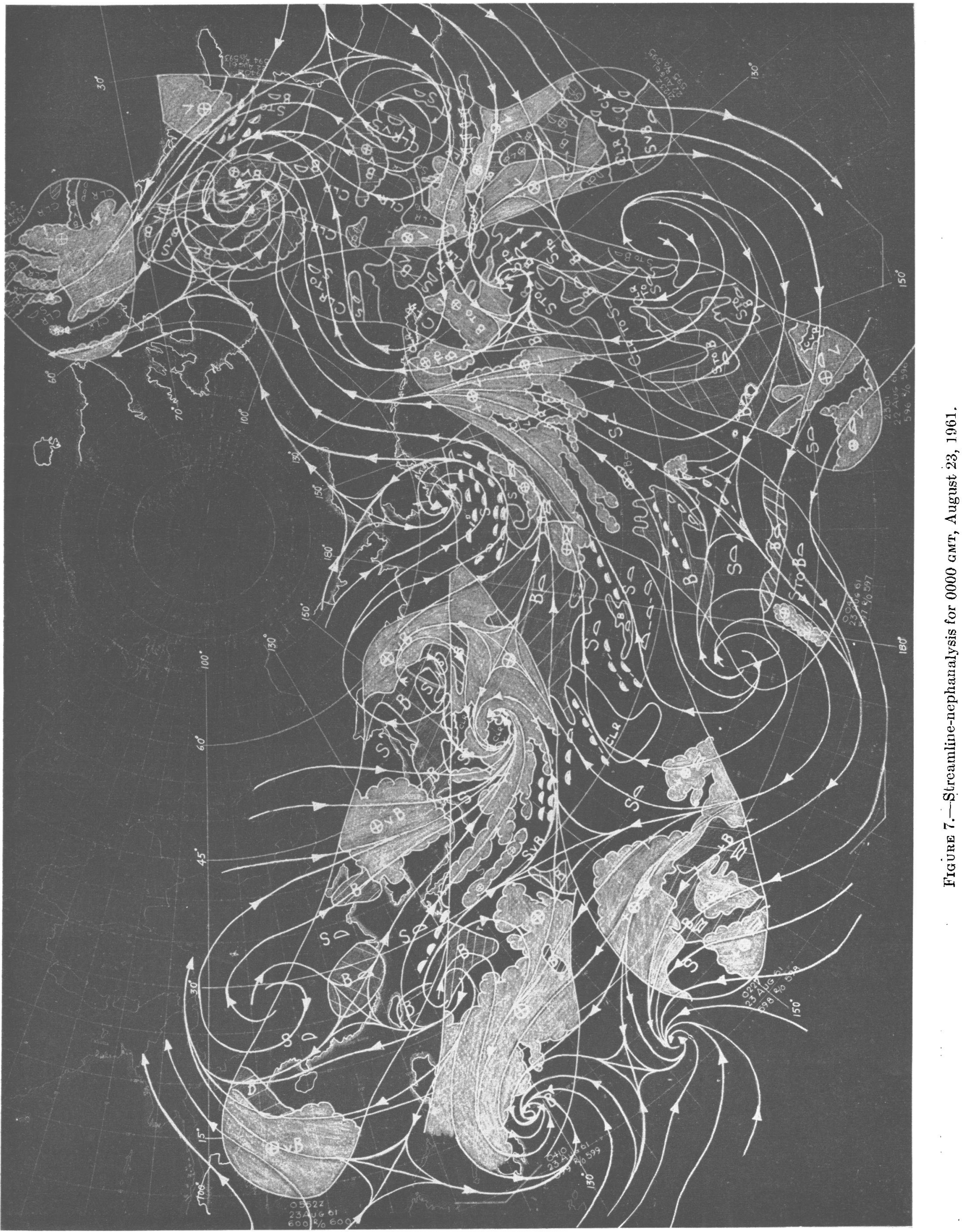




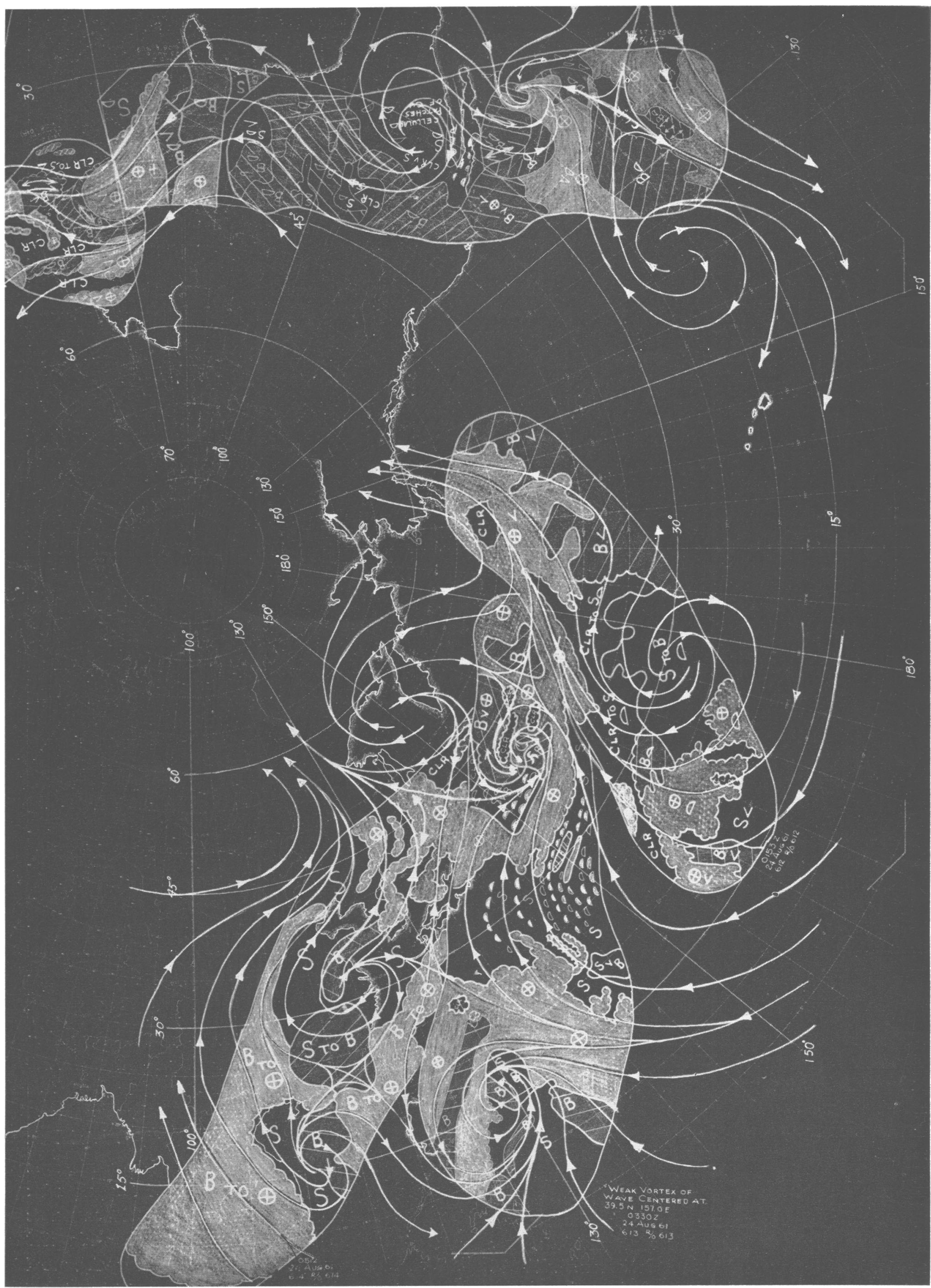

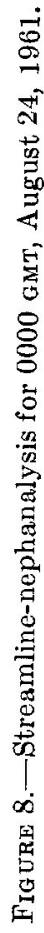




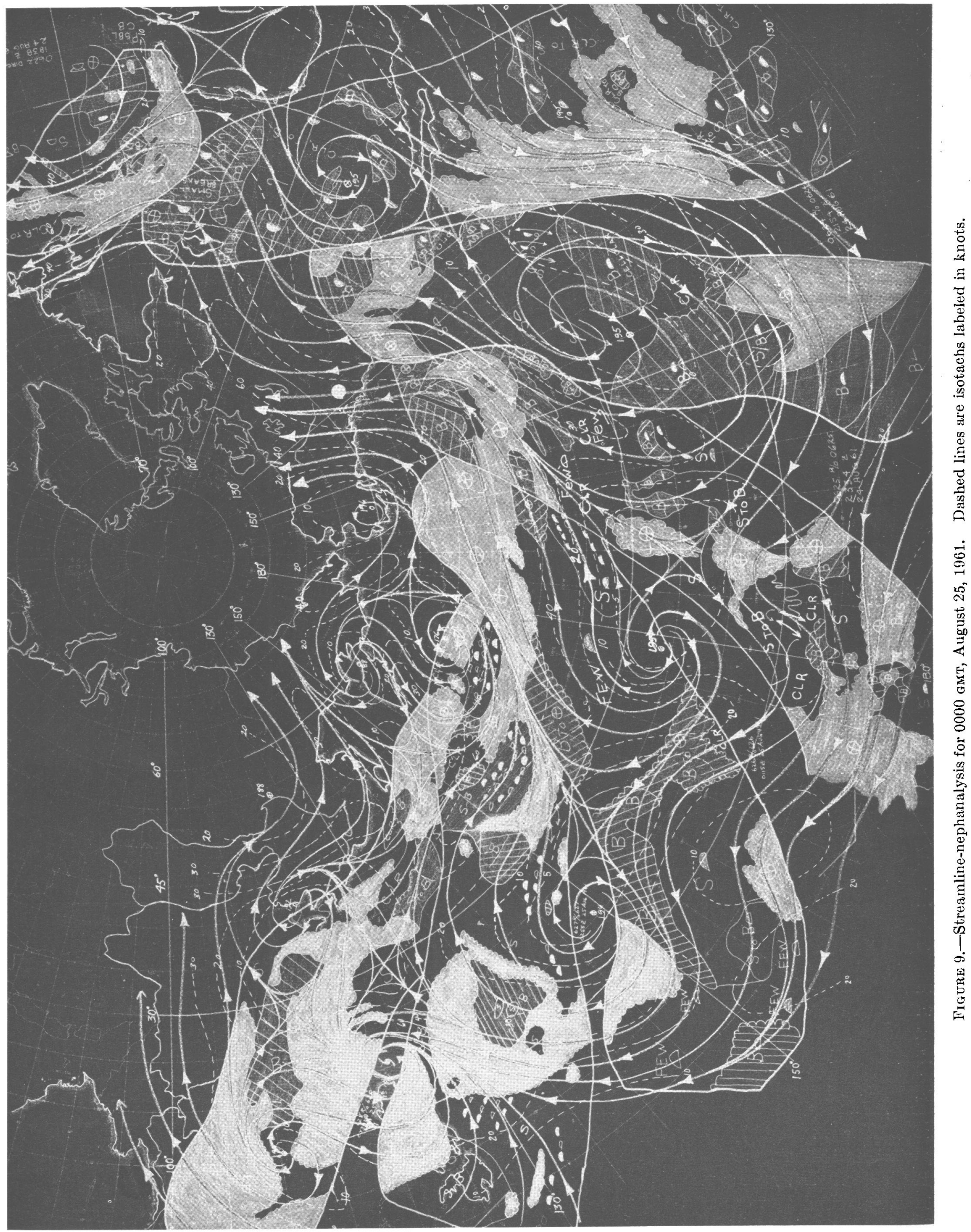




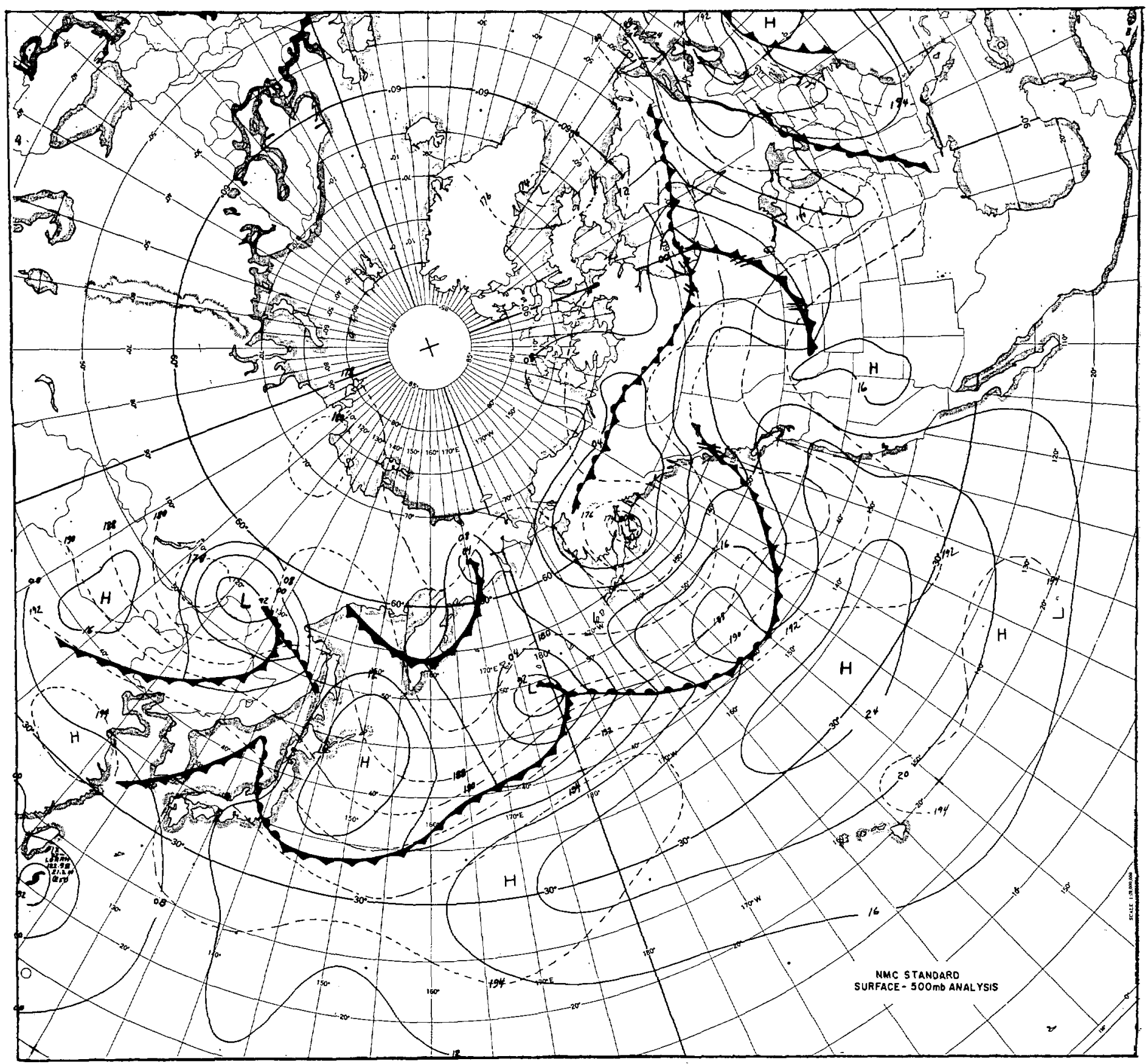

FIGURE 10.- Surface (solid lines) and 500-mb. (dashed lines) chart for 1200 GMT, August 24, 1961.

However, because of the reported heavy cloudiness over the southwestern Pacific, as shown by the nephananlyses in figures 8 and 9 , it was assumed that a pronounced tropical cyclone had generated in the vicinity of the Philippine Islands.

The original streamline analyses inferred from the nephanalyses for August 24 and 25 consisted of an easterly wave pattern at $500 \mathrm{mb}$. over the region north and east of the Philippines. Later when the NMC surface analysis for 0000 GMT, August 25 was reviewed, it was discovered that the assumed tropical disturbance was in fact typhoon
Lorna located at an estimated position of $21.2^{\circ} \mathrm{N} ., 122.9^{\circ}$ E. at $1200 \mathrm{GMT}$, August 24, 1961. The streamlines were then redrawn, as shown in figures 8 and 9 , to fit schematically a typhoon situation. This was done to determine the analytical effect of introducing a wind field and estimated $500-\mathrm{mb}$. central pressure of a typhoon into the NMC numerical analysis program. The result of the re-analysis is shown in figure 14A. The typhoon symbol in this figure is placed at the center of lowest $500-\mathrm{mb}$. contour values obtained in the re-analysis. The original NMC $500-\mathrm{mb}$. numerical analysis, figure $13 \mathrm{~B}$, did not reveal a developed tropical cyclone in this region. 


\section{APPLICATIONS TO NUMERICAL ANALYSIS}

Data from several of the streamline-isotach analyses obtained in the manner just described were introduced into the IBM 7090 computer analysis program at the National Meteorological Center. ${ }^{4}$ One procedure was to assume that the only data available for a $500-\mathrm{mb}$. analysis were monthly normal $500-\mathrm{mb}$. heights punched on cards and the streamline-nephanalyses. The $500-\mathrm{mb}$. normal heights were obtained from the Extended Forecast Branch of NMC and served as a first guess field for the numerical analysis. Wind directions and speeds were extracted at even $10^{\circ}$ latitude and longitude intersections from the deduced kinematic analyses to provide the additional data required for the numerical re-analyses. These data together with the estimated $500-\mathrm{mb}$. heights of the centers of vortices were punched on cards according to a specified format. The cards were then introduced in to a single run of the NMC computer program and the first guess field was modified to conform with the input data.

\section{THE MAY 1960 CASE}

For the May 1960 series described in section 5, the 500$\mathrm{mb}$. May normal heights were used as a first guess field. A contour print-out of this field for the region north of the subtropical ridge is shown in figure 11 to illustrate just how uninformative a $500-\mathrm{mb}$. normal contour chart can be for estimating the synoptic situation.

The North Pacific region outlined by the heavy lines in figures 11 and $12 \mathrm{~A}$ shows the $500-\mathrm{mb}$. re-analysis region. Figure $12 \mathrm{~A}$ shows the results obtained after applying the wind data and estimated heights for 0000 GMT, May 21, 1960 (fig. 5). The fronts superimposed over the $500-\mathrm{mb}$. re-analysis were taken from the NMC surface chart for $0000 \mathrm{GMT}$, May 21, 1960. The dashed lines in figure $12 \mathrm{~A}$ show the positions of the troughs and ridges of the NMC 500-mb. numerical analysis.

In addition to the pronounced definitive changes from the first guess normal field within the area outlined by the heavy line, there are several significant features worthy of note. First, the position of the belt of maximum westerlies and the low pressure centers, as shown by the re-analyzed contours of figure $12 \mathrm{~A}$, are in close agreement with the NMC analysis (fig. 12B) made with conventional data. Secondly, the major trough and ridge lines are in agreement with those in figure $12 \mathrm{~B}$, except for the trough line off the west coast of the United States. ${ }^{j}$ Outside the region of re-analysis, west of $100^{\circ} \mathrm{E}$. and east of $90^{\circ} \mathrm{W}$. the May normal contours were only slightly modified; inside the region the pattern was considerably modified and specified the synoptic situation reasonably well.

\footnotetext{
4 The NMC analysis program requires height values for each of the 1977 grid points to be used as a first guess. The program will accept both winds and heights as additional data for any desired region within the grid to be analyzed.

s A post analysis revealed that the west coast trough in figure $12 \mathrm{~B}$ could have had a position farther west on the 21st. This would have given a more uniform movement of the trough from May 20 to May 22, 1960.
}

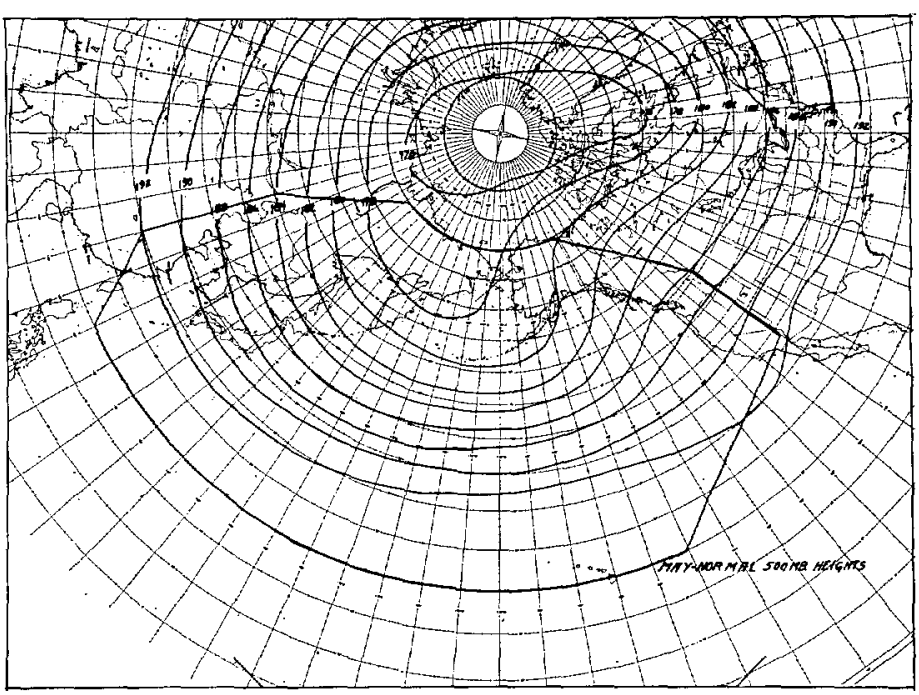

F'IGURE 11.-500-mib. monthly normal heights for May.

\section{THE AUGUST 1961 CASE}

A numerical re-analysis was also made of the August 25,1961 situation shown in figure 9 . In this case, it was assumed that the latest data available for a first guess were the NMC 48-hr. numerical forecast for $500 \mathrm{mb}$, displayed in figure $13 \mathrm{~A}$. The final re-analysis based on the nephanalyses and streamlines is shown in figure $14 \mathrm{~A}$, and the NMC numerical analysis used for verification is displayed in figure 13B. As a result of introducing data from the kinematic analysis a definite improvement over the furst guess 48 -hr. forecast was obtained in some areas: the trough over the central United States was better positioned; the low center off the Aleutian Islands was better defined; and some improvement in the positioning and definition of the subtropical ridge of the Pacific can be seen. The position and intensity of the belt of maximum westerlies over the North Pacific was also better defined by the re-analysis. The 500-mb. low center of the typhoon north of Luzon, P.I. was introduced into the re-analysis as described in section 6. However, the center, as determined by the lowest contour heights, was south of the reported position. The 24-hr. barotropic forecast shown in figure $14 \mathrm{~B}$ was obtained from the re-analysis (fig. 14A). This forecast revealed that the wind and 500-mb. height data introduced to obtain the re-analysis was satisfactory for the NMC barotropic forecast model. ${ }^{6}$ It should be pointed out here that in order to produce a reasonable numerical contour analysis from a $500-\mathrm{mb}$. monthly normal first guess, some estimate of the height at each center of action was required as well as the wind data.

\footnotetext{
a The troughs and ridges remained well positioned and the typhoon circulation was forecast in the correct direction but at too slow a speed.
} 

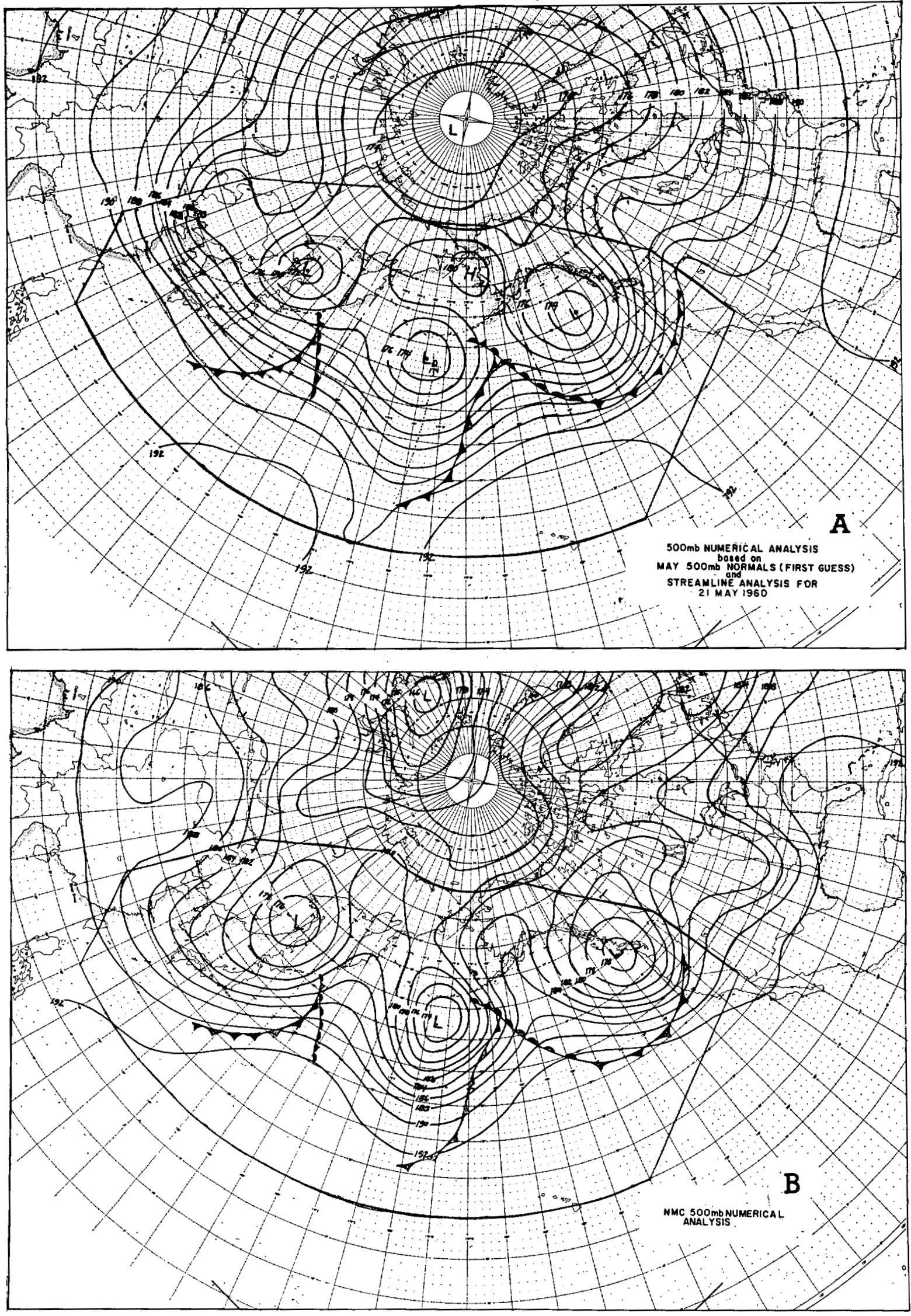

FIGURE 12.- (A) 500-mb. modified numerical analysis for 0000 GMT, May 21, 1960 . (B) National Meteorological Center 500-mb. numerical analysis for 0000 GarT, May 21, 1960. 

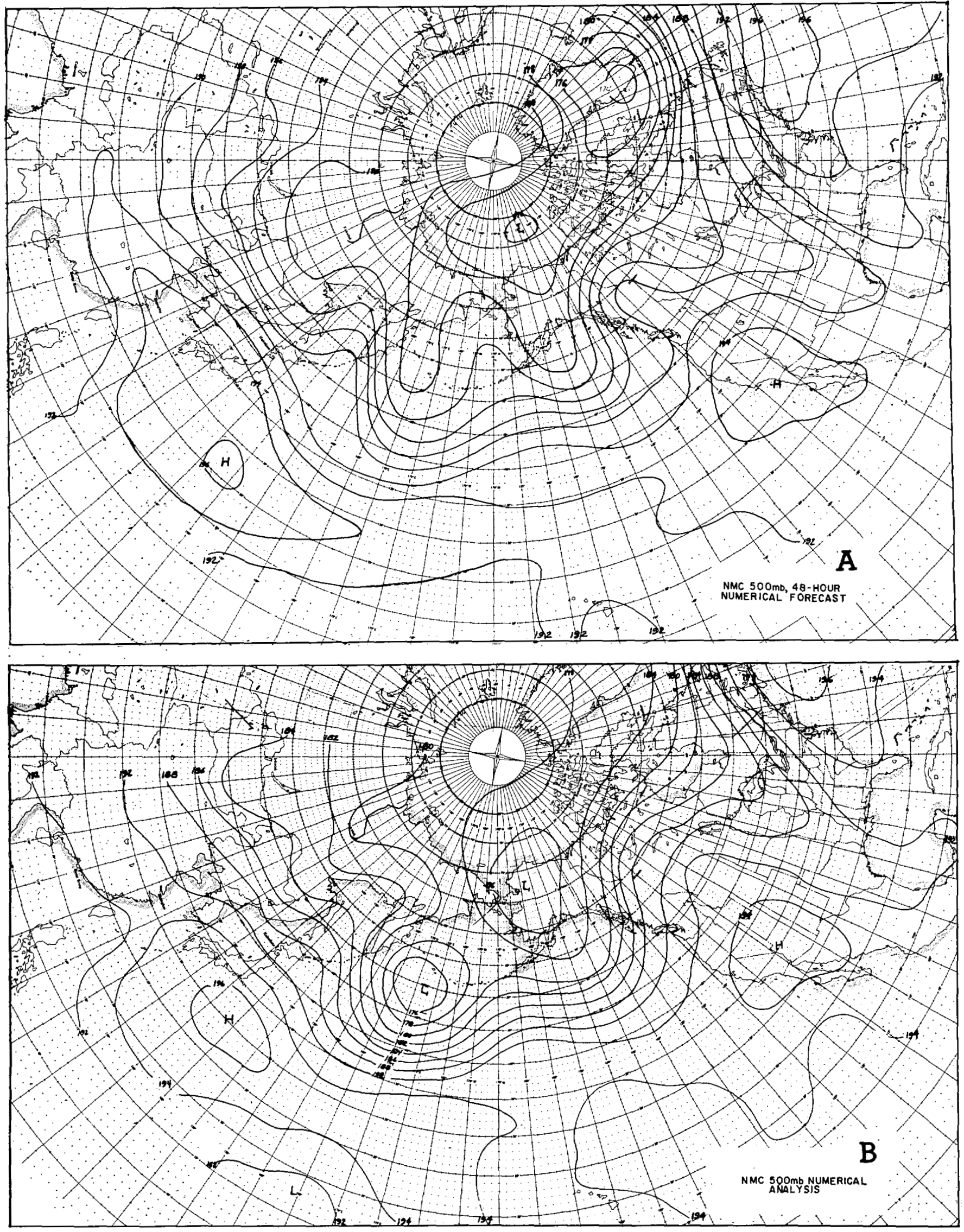

Frgure 13.-(A) National Meteorological Center 500-mb, 48-hr. numerical forecast valid 0000 GMr, August 25, 1961, and (B) the NMC 500-mb. numerical analysis for 0000 GMT, August 25, 1961. 

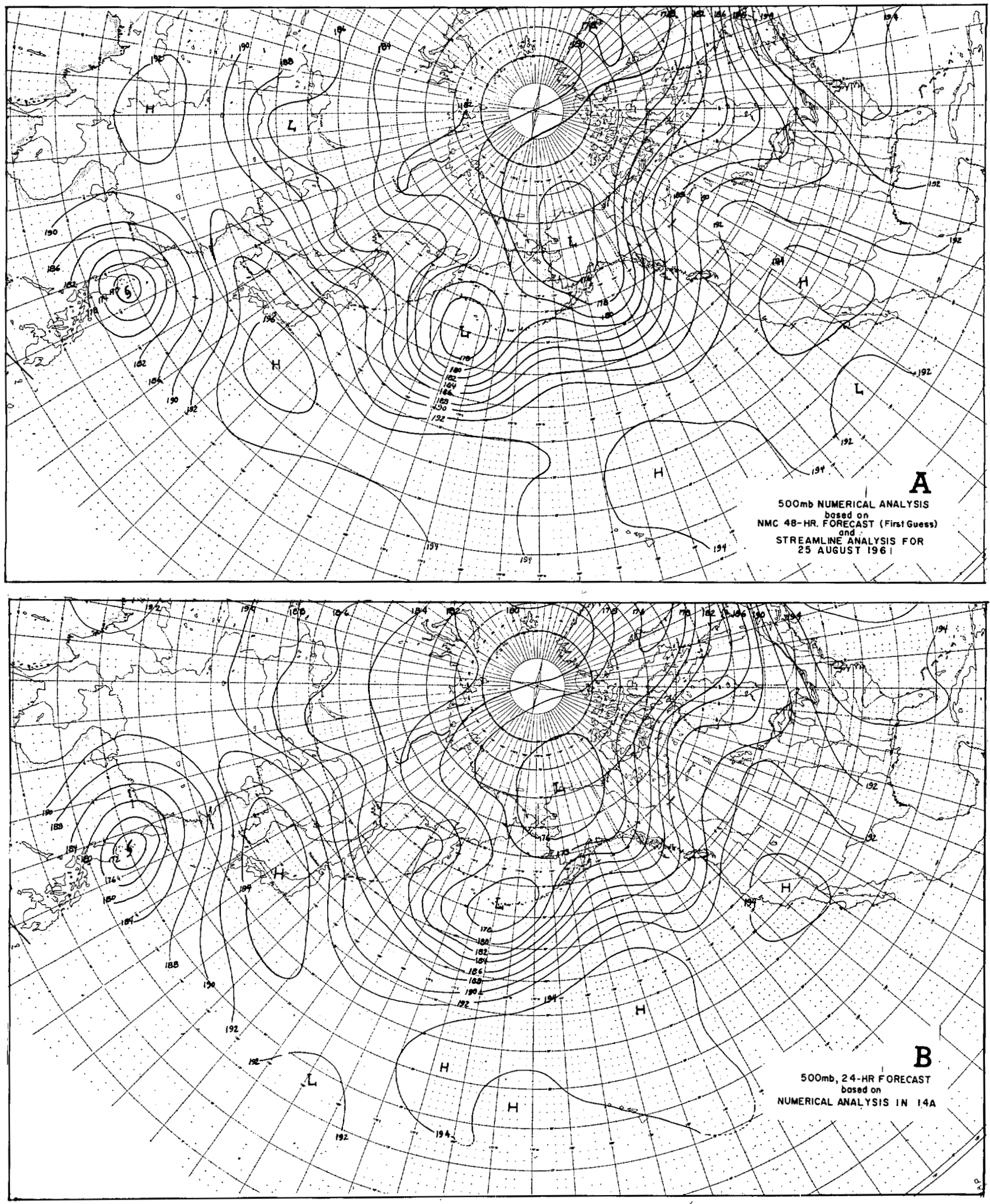

Frgure 14.--(A) 500 mb. modified numerical analysis for 0000 GMT, August 25, 1961, and (B) a 500-mb., 24-hr. numerical forecast based on the analysis in (A). 


\section{CONCLUSIONS}

From the above case studies and others not included, it seems plausible to conclude that a reasonable estimate of large-scale circulations for at least a middle level in the atmosphere can be deduced in most cases from TIROS cloud data. As one or more polar orbiting satellites are put into operation and new techniques for estimating cloud tops evolve, it may be speculated that kinematic analysis can be applied on a more nearly global scale, perhaps to more than one level. However, it is important to note that this approach is not intended to replace analyses based on conventional data. Over sparse data regions, particularly oceanic regions where upper-air observations are non-existent or few in space and time, this procedure can serve as an aid in estimating the largescale trough and ridge patterns, these inferred patterns constituting by no means unique solutions.

This method, by the very nature of its application and the data employed, is subjective and has very definite limitations. Nevertheless, it does provide a means of obtaining at least a qualitative analysis over sparse data regions where none could be made otherwise. Reasonably accurate and useful subjective analyses can be madeskill in kinematic analysis assumed-providing there is a judicious application of physical and statistical climatology to serve as an analytical control. A working knowledge of the relationships between weather and the field of motion as well as the ability to interpret satellite observations of clouds in terms of types, elevations, and the effects of orography on them are also important prerequisites for performing this type of analysis.

Two possible applications of this technique which can serve as an aid in analyzing over sparse data regions are suggested:

a. A direct application of the streamlines and isotachs can be made to estimate the wind field at the analysis level.

$b$. Wind speeds and directions extracted from the streamline-isotach analysis can be introduced into a computer analysis program; hence a numerical re-analysis provides conventional height contour analyses at the desired level.

\section{ACKNOWLEDGMENTS}

The author is especially grateful to Lt. Col. James B. Jones, USAF for his helpful suggestions and the detailed nephanalysis of the May 1960 series and to Mr. David S. Johnson and Dr. S. Fritz, all of the National Weather Satellite Center, for their encouragement and valuable comments. The generous assistance of members of Detachment 51, 1210th Weather Squadron, Air Weather Service in the preparation of the charts and numerical analyses is also gratefully acknowledged.

\section{REFERENCES}

1. S. Fritz, "Cloudiness Associated with Large-Scale Synoptic Systems in Temperate Latitudes," Proceedings of the Inter. national Meteorological Satellite Workshop, NASA-U.S. Weather Bureau, Washington, D.C., Nov. 1961, pp. 45-65.

2. S. Fritz, "Satellite Cloud Pictures of a Cyclone over the Atlantic Ocean," Quarterly Journal of the Royal Meteorological Sociely, vol. 87, No. 373, July 1961, pp. 314-321.

3. S. Fritz and J. S. Winston, "Synoptic Use of Radiation Measurements from Satellite TIRCS II," Monthly Weather Review, vol. 90, No. 1, Jan. 1962, pp. 1-9.

4. J. B. Jones, "A Western Atlantic Vortex Seen by TIRoS I," Monthly Weather Review, vol. 89, No. 10, Oct. 1961, pp. $383-390$.

5. J. Kuettner, "The Band Structure of the Atmosphere," Tellus, vol. 11, No. 3, Aug. 1959, pp. 267-294.

6. V. J. Oliver, "TIRCS Fills the Void for World Weather Watch," Weatherwise, vol. 15, No. 4, Aug. 1962, pp. 160-162.

7. C. S. Ramage, "The Subtropical Cyclone," Journal of Geophysical Research, vol. 67, No. 4, Apr. 1962, pp. 1401-1411.

8. J. Sadler, "Utilization of Meteorological Satellite Cloud Data in Tropical Meteorology," Research Note, Air Force Cambridge Research Laboratory, 62-829, Aug. 1962.

9. N. Shaw, Manual of Meteorology, Vol. I, Cambridge University Press, 1926, 339 pp. (p. 208).

10. L.S. Weather Bureau, "Normal Weather Charts for the Northern Hemisphere," Technical Paper No. 21, Washington, October $1952,74 \mathrm{pp}$.

11. H. Wexler, "TIRCS Experiment Results," Space Science Reviews, vol. 1, 1962, pp. 7-27.

12. C. J. Wiederanders, "Analyses of Monthly Mean Resultant Winds for Standard Pressure Levels over the Pacific," Science Report No. 3, Contract No. AF 19(604)-7229, University of Hawaii, Mar. 1961.

13. J. S. Winston, "Satellite Picture of a Cut-Off Cyclone over the Eastern Pacific," Monthly Weather Review, vol. 88, Nos. 9-12, Sept.-Dec. 1960, pp. 295-314. 